\title{
The recent trend of plagiarism in Nepal.
}

The recent publication of plagiarism in the national paper in Nepal has brought into focus regarding this menace (Figure 1). ${ }^{3}$ The nature by which the articles had been copied in word to word "copy and paste" format except the data is really a shame to medical research in this country. This will hopefully help to check plagiarism in this country. There have been very few articles regarding this issue from Nepal and hence I have included this as a review article in this issue. ${ }^{1,3,4}$
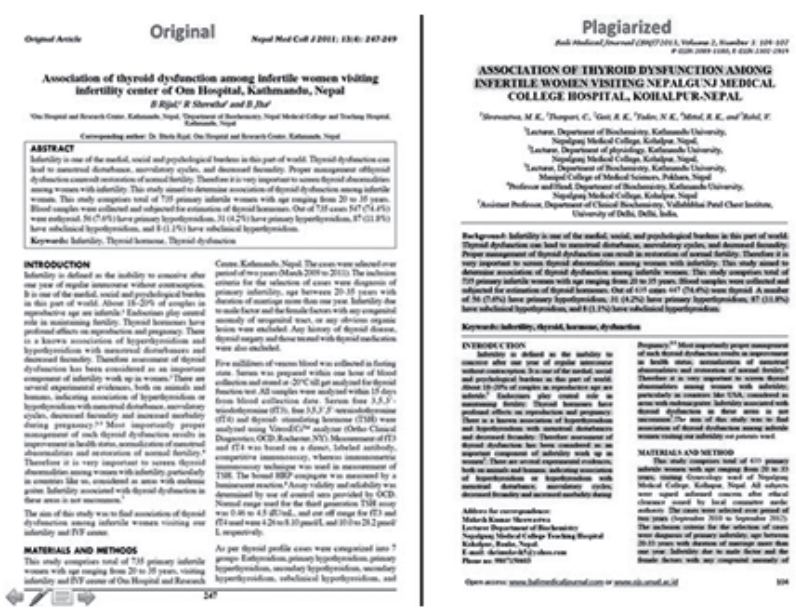

Figure 1:Republica post showing the plagiarism by Nepali doctors. ${ }^{3}$

The exact prevalence of plagiarism in Nepal is unknown but there have been reports of it not onlyfrom the medical but also in non-medical sectors. Various reports from the oldest university in Nepal, Tribhuvan University have shown that it does exist. ${ }^{2,4}$ Reports of the buying and use of plagiarism checking program at Tribhuvan university was also in the news but whether it has been bought or not remains unknown.There are no specific laws regarding plagiarism in Nepal although the Copyright Act of 2059 B.S. will address some of this issue. The penalty ranges from $10 \mathrm{~K}-1$ lakh or 6 months in prison or both for the $1 \mathrm{st}$ offence and, $20 \mathrm{~K}$ - 2 lakhs or 1 year in prison or both for 2nd offence onwards ${ }^{4}$. The review article in this issue will further deal with this problem and also regarding the ways to avoid plagiarism.

\section{References:}

1. Avoiding Plagiarism and Self-Plagiarism. Journal of Nepal Paediatric Society: 30.22010

2. Beyond Plagiarism: How honest research could be promoted in Nepal. http://archive.setopati.net/ opinion/16820/Beyond-Plagiarism:-How-honestresearch-could-be-promoted-in-Nepal/2018

3. Five KU docs found plagiarizing research findings. http://www.myrepublica.com/news/28926/ november 2016

4. Plagiarism in Nepal: Writing without worries. http:// nepalibytes.com/plagiarism-in-nepal-writingwithout-worries/2016 